University of Warwick institutional repository: http://go.warwick.ac.uk/wrap This paper is made available online in accordance with publisher policies. Please scroll down to view the document itself. Please refer to the repository record for this item and our policy information available from the repository home page for further information.

To see the final version of this paper please visit the publisher's website. Access to the published version may require a subscription.

Author(s): P. D. C. King, T. D. Veal, P. H. Jefferson, C. F. McConville, T. Wang, P. J. Parbrook, Hai Lu and W. J. Schaff

Article Title: Valence band offset of InN/AIN heterojunctions measured by x-ray photoelectron spectroscopy

Year of publication: 2007

Link to published version: http://dx.doi.org/ 10.1063/1.2716994

Publisher statement: None 


\title{
Valence band offset of InN/AIN heterojunctions measured by x-ray photoelectron spectroscopy
}

\author{
P. D. C. King, T. D. Veal, P. H. Jefferson, and C. F. McConville ${ }^{a)}$ \\ Department of Physics, University of Warwick, Coventry CV4 7AL, United Kingdom \\ T. Wang and P. J. Parbrook \\ EPSRC National Centre for III-V Technologies, Department of Electronic and Electrical Engineering, \\ University of Sheffield, Mappin Street, Sheffield S1 3JD, United Kingdom \\ Hai Lu ${ }^{\text {b) }}$ and W. J. Schaff \\ Department of Electrical and Computer Engineering, Cornell University, Ithaca, New York 14853
}

(Received 18 January 2007; accepted 20 February 2007; published online 27 March 2007)

\begin{abstract}
The valence band offset of wurtzite-InN/AlN (0001) heterojunctions is determined by $\mathrm{x}$-ray photoelectron spectroscopy to be $1.52 \pm 0.17 \mathrm{eV}$. Together with the resulting conduction band offset of $4.0 \pm 0.2 \mathrm{eV}$, a type-I heterojunction forms between $\mathrm{InN}$ and $\mathrm{AlN}$ in the straddling arrangement. (C) 2007 American Institute of Physics. [DOI: 10.1063/1.2716994]
\end{abstract}

The band gaps of group III-N semiconductors span an extremely wide range from a now generally accepted zerotemperature value of approximately $0.7 \mathrm{eV}$ for InN (Refs. 1 and 2) to approximately $6.25 \mathrm{eV}$ for $\mathrm{AlN}^{3}$ This introduces the possibility for III-N alloys and heterostructures to be used in a wide variety of optoelectronic devices, where a large variation in the operating wavelength range of the device is required. Of crucial importance to the design of such devices is an accurate characterization of the band offsets. The band offset at InN/AlN heterojunctions has received interest both experimentally ${ }^{4,5}$ and theoretically. ${ }^{6,7}$ However, there has been a large variation both within and between the measured and theoretical values reported previously. In addition, a number of these studies ${ }^{5,6}$ were performed before the revision of the InN band gap from the previously accepted value of $1.89 \mathrm{eV}^{8}$, and so these results should be reevaluated in light of this change. In this letter, we present a determination of the wurtzite-InN/AIN band offsets using $\mathrm{X}$-ray photoelectron spectroscopy (XPS).

The InN and InN/AIN samples were grown on $c$-plane sapphire substrates by plasma assisted molecular-beam epitaxy at growth temperatures of $480{ }^{\circ} \mathrm{C}$ for the InN layers and $800{ }^{\circ} \mathrm{C}$ for the AlN layers. Details of the growth are reported elsewhere. ${ }^{9}$ The InN sample had a layer thickness of $310 \mathrm{~nm}$ and a carrier concentration and electron mobility measured by the single-field Hall effect of $2 \times 10^{18} \mathrm{~cm}^{-3}$ and $1100 \mathrm{~cm}^{2} \mathrm{~V}^{-1} \mathrm{~s}^{-1}$, respectively. The InN/AlN sample consisted of a thin layer of InN grown on a $200 \mathrm{~nm}$ layer of AIN. The InN layer thickness was estimated at $4.5 \mathrm{~nm}$ from growth-rate calibrations and at $4.6 \mathrm{~nm}$ by considering the variation of intensity of the Al $2 p$ XPS core level peak with take-off angle due to the exponential attenuation of photoelectrons by the InN overlayer described by the BeerLambert law. The inelastic mean free path of the photoelectrons in the InN layer was calculated using the TPP-2M predictive formula of Tanuma et al. ${ }^{10}$ The carrier sheet density and electron mobility measured by the single-field Hall effect were $5 \times 10^{13} \mathrm{~cm}^{-2}$ and $10 \mathrm{~cm}^{2} \mathrm{~V}^{-1} \mathrm{~s}^{-1}$, respectively.

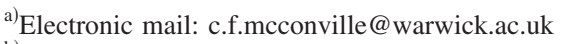

${ }^{b)}$ Present address: Department of Physics, Nanjing University, Nanjing 210093, China.
}

The AlN film was grown to a thickness of $1 \mu \mathrm{m}$ on a $c$-plane sapphire substrate at a temperature of $1150{ }^{\circ} \mathrm{C}$ by metalorganic chemical vapor deposition. ${ }^{11}$

The XPS measurements were performed at room temperature using a Scienta ESCA300 spectrometer at the National Centre for Electron Spectroscopy and Surface analysis, Daresbury Laboratory, UK. Details of the spectrometer and its arrangement are reported elsewhere. ${ }^{12}$ The position of the valence band maximum (VBM) is calculated by extrapolating a linear fit to the leading edge of the valence band photoemission to the background level in order to take account of the finite resolution $(0.45 \mathrm{eV})$ of the spectrometer. ${ }^{13}$ A low-energy electron flood gun was utilized for the measurements of the AlN sample to achieve charge compensation. Calibration to a universal energy reference was not required as it is the relative energy separation of spectral features that is of importance for the determination of a valence band offset (VBO).

Measurements are presented for as-loaded (oxidized) samples due to the difficulty in cleaning the samples without causing electronic damage. ${ }^{14,15}$ This is especially important for the InN/AlN sample, where cleaning could additionally cause significant reduction in the thickness of the already very thin InN layer. Investigation of the In $3 d, \mathrm{Al} 2 p, \mathrm{~N} 1 s$, $\mathrm{C} 1 s$, and $\mathrm{O} 1 s$ core level peaks from XPS indicated III-O oxide components but not significant $\mathrm{N}-\mathrm{O}$ bonding. Adventitious hydrocarbons were also identified on the surface.

The In $3 d$ core level peaks for the $\mathrm{InN}$ and InN/AlN samples, the Al $2 p$ core level peaks for the AIN and InN/AIN samples, and the valence band photoemission for the $\mathrm{InN}$ and AlN samples are shown in Fig. 1. All peaks have been fitted using a Shirley background (incorporating a linear component) and Voigt (mixed Lorentzian-Gaussian) line shapes. The peak parameters and valence band maximum positions are listed in Table I. The spin-orbit split In $3 d$ peaks in both the InN and InN/AlN samples are seen to consist of three components. The lowest binding energy component is associated with In bonded to $\mathrm{N}$. The higher ratio of the In-N peak intensity to the (higher binding energy) contaminant related peaks for the InN sample compared to the InN/AIN sample is consistent with the relative thicknesses of the InN layer in the two samples. The higher binding energy peaks 


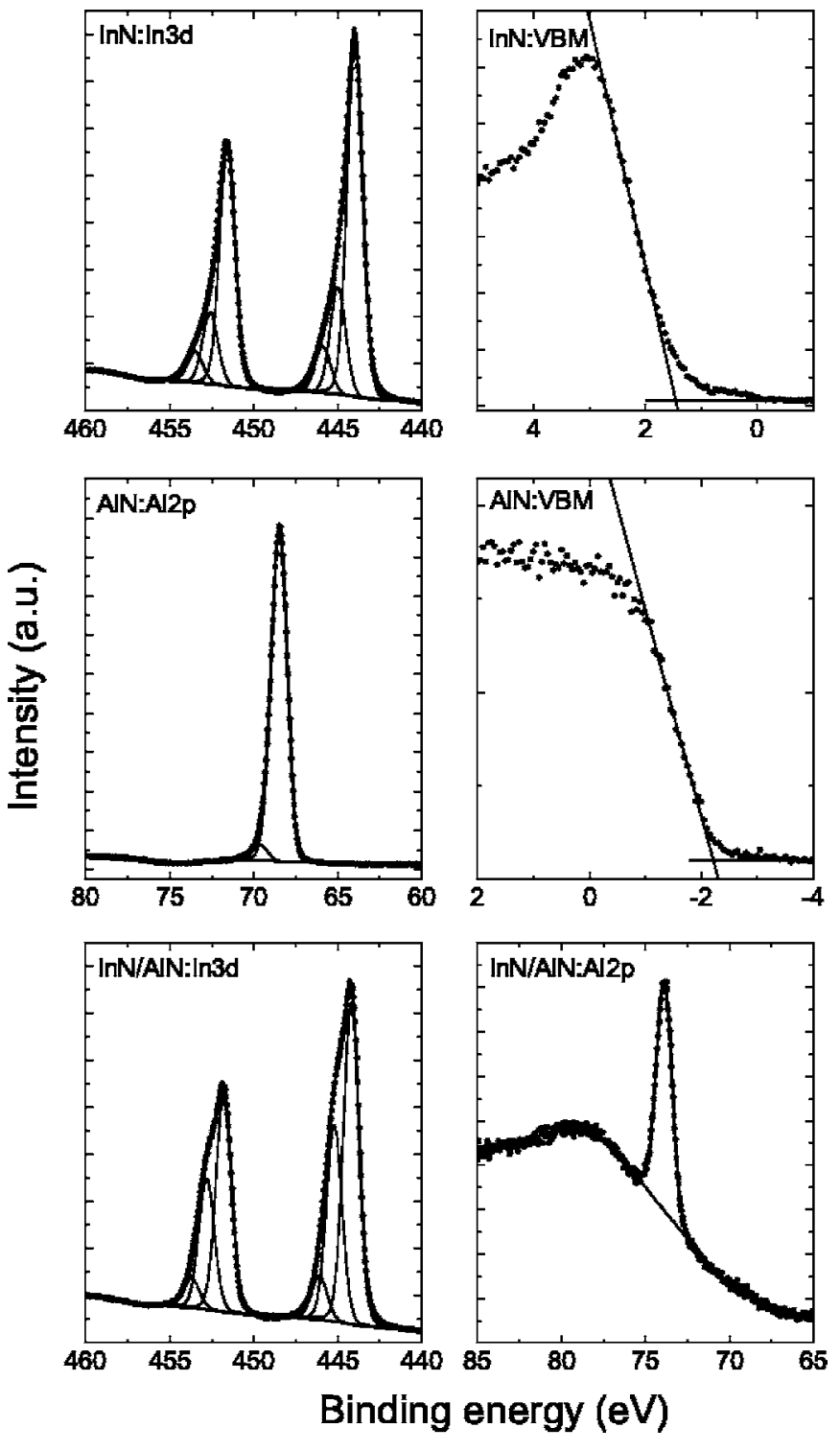

FIG. 1 . In $3 d$ core level peaks for the InN and InN/AlN samples, Al $2 p$ core level peaks for THE AlN and InN/AlN samples, and valence band photoemission for the InN and AlN samples. All peaks have been fitted using a Shirley background with a linear component and Voigt (mixed LorentzianGaussian) line shapes as shown.

are identified as being due to surface contamination. Comparison of their binding energy separation with previous results $^{18}$ suggests assignments of In-O bonding (from the oxidized surface, $\left.\mathrm{In}_{2} \mathrm{O}_{3}\right)$ and $\mathrm{In}-(\mathrm{OH})_{3}$ bonding for the midand highest-binding energy components, respectively. The $\mathrm{Al} 2 p$ peak is composed of a single component ( $\mathrm{Al}-\mathrm{N}$ bonding) in the InN/AlN sample as the AlN layer is below the surface and so does not have an oxide component. The spinorbit splitting of the Al2 $p$ peak is not resolvable in Fig. 1, but is included in the fitting. In the AlN sample, an additional small peak was required to fit the spectrum at high binding energies, consistent with $\mathrm{Al}-\mathrm{O}$ bonding due to the oxide contamination when AlN is present at the surface. The valence band photoemission for the AlN sample with negative VBM binding energy shows the shift in binding energy due to the operation of the flood gun. However, as discussed above, this was not corrected for as only relative separations of the spectral features in each sample were required.

The VBO was calculated from The VBO was calculated from of an InN/AIN heterojunction as $1.52 \pm 0.17 \mathrm{eV}$. This is
Downloaded 01 Jul 2009 to 137.205.202.8. Redistribution subject to AIP license or copyright; see http://apl.aip.org/apl/copyright.jsp
TABLE I. Parameters (binding energy, full width at half maximum (FWHM), Lorentzian to percentage of the Voigt line shape $(L)$, and spin-orbit splitting $\left(\Delta_{\mathrm{so}}\right)$ of the peaks used in the core level fitting and the valence band photoemission extrapolations used to fit the XPS data shown in Fig. 1. No correction for the shift in binding energies due to the operation of the flood gun has been applied for the AlN sample as this does not affect the relative separation of the spectral features.

${ }^{a}$ The listed values are for the $\operatorname{In} 3 d_{5 / 2}$ peak. The $\operatorname{In} 3 d_{3 / 2}$ width and Lorentzian-Gaussian parameters are the same, with the binding energy shifted by the spin-orbit splitting, $\Delta_{\text {so }}$, and the peak area scaled in the ratio of 3:2 due to the spin-orbit coupling strengths.

${ }^{\mathrm{b}}$ From Pessa et al. (Ref. 16).

${ }^{\mathrm{c}}$ The listed values are for the $\mathrm{A} 12 p_{3 / 2}$ peak. The $\mathrm{Al} 2 p_{1 / 2}$ width and Lorentzian-Gaussian parameters are the same, with the binding energy shifted by the spin-orbit splitting, $\Delta_{\mathrm{so}}$, and the peak area scaled in the ratio of 2:1 due to the spin-orbit coupling strengths.

${ }^{\mathrm{d}}$ From Barrie et al. (Ref. 17).

$$
\Delta E_{V}=\Delta E_{\mathrm{CL}}+\left(E_{\mathrm{In} 3 d}^{\mathrm{InN}}-E_{V}^{\mathrm{InN}}\right)-\left(E_{\mathrm{Al} 2 p}^{\mathrm{AlN}}-E_{V}^{\mathrm{AlN}}\right),
$$

where $E_{V}^{\mathrm{A}}$ denotes the $\mathrm{VBM}$ in material $\mathrm{A}, E_{B}^{\mathrm{A}}$ denotes the energy of the core level $B$ in material $\mathrm{A}$, and $\Delta E_{\mathrm{CL}}$ is the energy separation of the Al $2 p$ and In $3 d$ core level peaks in the InN/AlN sample. Using the In-N bonding component of the $\operatorname{In} 3 d_{5 / 2}$ and the $\mathrm{Al}-\mathrm{N}$ bonding component of the $\mathrm{Al} 2 p_{3 / 2}$ core level peaks, the InN/AlN VBO is calculated as $1.52 \pm 0.17 \mathrm{eV}$. This value is comparable to, although slightly lower than, the experimental value of $1.81 \pm 0.20 \mathrm{eV}$ determined from XPS by Martin et al. ${ }^{5}$ and significantly lower than the value of $3.10 \pm 0.04 \mathrm{eV}$ recently determined (from photoelectron spectroscopy utilizing $110 \mathrm{eV}$ incident photons) by $\mathrm{Wu}$ et al. ${ }^{4}$ The theoretically determined values of the VBO are close to or somewhat lower than the experimental value reported here $(1.46 \mathrm{eV}$ calculated from charge neutrality levels determined from empirical tight-binding calculations, ${ }^{19} 1.25 \mathrm{eV}$ using a first-principles general potential linearized augmented plane wave method ${ }^{6}$ and $0.97 \mathrm{eV}$ calculated from charge neutrality levels determined from Green's functions ${ }^{7}$ ) with better agreement seen here than with previous experimental studies.

The room temperature band gaps of InN $[0.64 \mathrm{eV}$ (Ref. 2)] and of AlN [6.16 eV (Ref. 3)], calculated from the zerotemperature values and Varshni parameters, allow the band lineup to be determined, as shown in Fig. 2. The resulting conduction band offset is therefore calculated as $4.0 \pm 0.2 \mathrm{eV}$. A type-I heterojunction is seen to be formed in the straddling configuration.

\begin{tabular}{|c|c|c|c|c|c|c|}
\hline Sample & Region & Bonding & $\begin{array}{c}\text { Binding } \\
\text { energy } \\
(\mathrm{eV})\end{array}$ & $\begin{array}{c}\text { FWHM } \\
(\mathrm{eV})\end{array}$ & $L(\%)$ & $\begin{array}{c}\Delta_{\text {so }} \\
(\mathrm{eV})\end{array}$ \\
\hline \multirow[t]{4}{*}{$\mathrm{InN} / \mathrm{AlN}$} & $\operatorname{In} 3 d^{\mathrm{a}}$ & In-N & $444.18 \pm 0.05$ & 1.09 & 8 & $7.6^{\mathrm{b}}$ \\
\hline & & In-O & $445.20 \pm 0.05$ & 1.09 & 8 & 7.6 \\
\hline & & $\mathrm{In}-(\mathrm{OH})_{3}$ & $446.09 \pm 0.05$ & 1.09 & 8 & 7.6 \\
\hline & $\mathrm{Al} 2 p^{\mathrm{c}}$ & Al-N & $73.74 \pm 0.05$ & 0.99 & 8 & $0.45^{\mathrm{d}}$ \\
\hline \multirow[t]{4}{*}{ InN } & $\operatorname{In} 3 d^{\mathrm{a}}$ & In-N & $443.96 \pm 0.05$ & 1.09 & 8 & 7.6 \\
\hline & & In-O & $444.98 \pm 0.05$ & 1.09 & 8 & 7.6 \\
\hline & & $\mathrm{In}-(\mathrm{OH})_{3}$ & $445.87 \pm 0.05$ & 1.09 & 8 & 7.6 \\
\hline & VBM & $\cdots$ & $1.45 \pm 0.1$ & & & $\cdots$ \\
\hline \multirow[t]{3}{*}{ AlN } & $\mathrm{A} 12 p^{\mathrm{c}}$ & $\mathrm{Al}-\mathrm{N}$ & $68.34 \pm 0.05$ & 0.99 & 8 & 0.45 \\
\hline & & $\mathrm{Al}-\mathrm{O}$ & $69.50 \pm 0.05$ & 0.99 & 8 & 0.45 \\
\hline & VBM & $\cdots$ & $-2.21 \pm 0.1$ & $\cdots$ & $\cdots$ & $\cdots$ \\
\hline
\end{tabular}

In conclusion, we have measured the valence band offset 


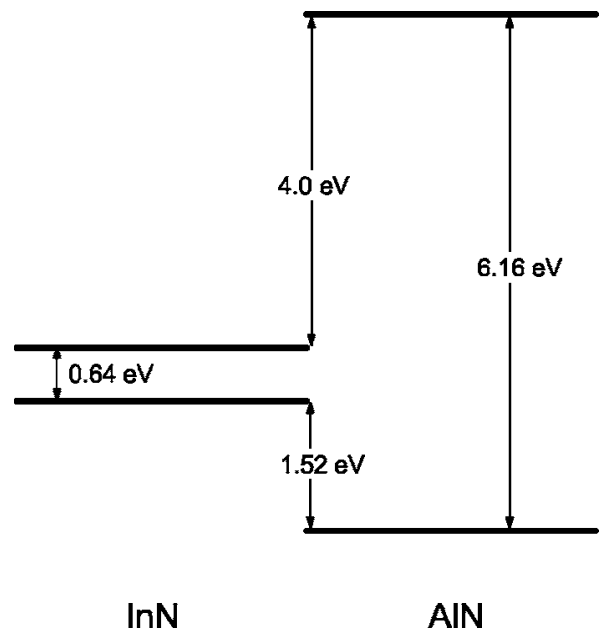

FIG. 2. Schematic representation of the band lineup at an InN/AlN heterojunction at room temperature. A type-I heterojunction is formed in the straddling configuration.

similar, although somewhat higher, than previous theoretical calculations, and somewhat lower than previous experimental results. This offset causes a type-I heterojunction to form between InN and AlN in the straddling arrangement.

The authors are grateful to Danny Law and Graham Beamson of NCESS for their assistance with XPS measurements. Also acknowledged are the Engineering and Physical Sciences Research Council, UK, for financial support under Grant No. EP/C535553/1 and for access to the NCESS facility under Grant No. GR/S14252/01.
${ }^{1}$ J. Wu, W. Walukiewicz, K. M. Yu, J. W. Ager, III, E. E. Haller, H. Lu, W. J. Schaff, Y. Saito, and Y. Nanishi, Appl. Phys. Lett. 80, 3967 (2002).

${ }^{2}$ J. Wu, W. Walukiewicz, W. Shan, K. M. Yu, J. W. Ager, III, S. X. Li, E.

E. Haller, H. Lu, and W. J. Schaff, J. Appl. Phys. 94, 4457 (2003).

${ }^{3}$ I. Vurgaftman and J. R. Meyer, J. Appl. Phys. 94, 3675 (2003).

${ }^{4}$ C.-L. Wu, C.-H. Shen, and S. Gwo, Appl. Phys. Lett. 88, 032105 (2006).

${ }^{5}$ G. Martin, A. Botchkarev, A. Rockett, and H. Morkoç, Appl. Phys. Lett. 68, 2541 (1996).

${ }^{6}$ S.-H. Wei and A. Zunger, Appl. Phys. Lett. 69, 2719 (1996).

${ }^{7}$ J. Robertson and B. Falabretti, J. Appl. Phys. 100, 014111 (2006).

${ }^{8}$ T. L. Tansley and C. P. Foley, J. Appl. Phys. 59, 3241 (1986).

${ }^{9}$ W. J. Schaff, H. Lu, L. F. Eastman, W. Walukiewicz, K. M. Yu, S. Keller, S. Kurtz, B. Keyes, and L. Gevilas, The Electrochemical Society Proceedings Series, Honolulu, Hawaii, 3-8 October 2004, edited by H. M. Ng and A. G. Baca (Electrochemical Society, Pennington, NJ, 2004), Vol. 2004-06, pp. 358-371.

${ }^{10}$ S. Tanuma, C. J. Powell, and D. R. Penn, Surf. Interface Anal. 21, 165 (1994).

${ }^{11}$ T. Wang, J. Bai, P. J. Parbrook, and A. G. Cullis, Appl. Phys. Lett. 87, 151906 (2005).

${ }^{12}$ T. D. Veal, P. H. Jefferson, L. F. J. Piper, C. F. McConville, T. B. Joyce, P. R. Chalker, L. Considine, H. Lu, and W. J. Schaff, Appl. Phys. Lett. 89, 202110 (2006).

${ }^{13}$ S. A. Chambers, T. Droubay, T. C. Kaspar, and M. Gutowski, J. Vac. Sci. Technol. B 22, 2205 (2004).

${ }^{14}$ S. Krischok, V. Yanev, O. Balykov, M. Himmerlich, J. A. Schaefer, R. Kosiba, G. Ecke, I. Cimalla, V. Cimalla, and O. Ambacher, Surf. Sci. 566-568, 849 (2004).

${ }^{15}$ L. F. J. Piper, T. D. Veal, M. Walker, I. Mahboob, C. F. McConville, H. Lu, and W. J. Schaff, J. Vac. Sci. Technol. A 23, 617 (2005).

${ }^{16}$ M. Pessa, A. Vuoristo, M. Vulli, S. Aksela, J. Väyrynen, T. Rantala, and H. Aksela, Phys. Rev. B 20, 3115 (1979).

${ }^{17}$ A. Barrie, I. W. Drummond, and Q. C. Herd, J. Electron Spectrosc. Relat. Phenom. 5, 217 (1974).

${ }^{18}$ L. L. Kazmerski, P. J. Ireland, P. Sheldon, T. L. Chu, S. S. Chu, and C. L. Lin, J. Vac. Sci. Technol. 17, 1061 (1980).

${ }^{19}$ W. Mönch, J. Appl. Phys. 80, 5076 (1996). 